Estival. K.G.S.; Behrmann, D.G.M; Barbosa, C.R.; Corrêa, S.R.S.; Mariani, M.A.P. Resistência dos mercados tradicionais: análise mercadológica da Feira do Malhado em llhéus (BA) sob as perspectivas dos consumidores. Revista Brasileira de Ecoturismo, São Paulo, v.9, n.2, mai/jul 2016, pp.346-365.

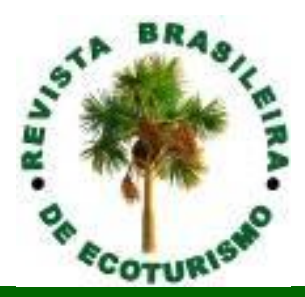

\title{
A Resistência dos mercados tradicionais: análise mercadológica da Feira do Malhado em Ilhéus (BA) sob as perspectivas dos consumidores
}

\section{Quality The resistance of traditional markets: market analysis at the Malhado Fair in Ilhéus (Bahia, Brazil) under the consumers' perspective}

Katianny Gomes Santana Estival, Daianne Gabrielle Morais Behrmann, Camila Rusciolelli Barbosa, Solange Rodrigues Santos Corrêa, Milton Augusto Pasquotto Mariani

\begin{abstract}
RESUMO
As feiras de comercialização de produtos regionais nos espaços urbanos são identificadas como locais de resistência e sobrevivência dos mercados frente a expansão dos supermercados. Conservam características que atraem os consumidores que procuram bom atendimento, variedade de produtos e serviços, principalmente de produtos regionais, apesar de não oferecerem o mesmo padrão da infraestrutura física, higiene e limpeza dos supermercados. Neste contexto o trabalho apresenta os resultados da pesquisa exploratória realizada junto aos consumidores da Feira do Malhado no ano de 2014, na cidade de Ilhéus, Bahia, Brasil, e a análise do seu ambiente estratégico SWOT, as forças, fraquezas (ambiente interno da organização), oportunidades e ameaças do macroambiente. Os resultados obtidos apontaram que a Feira do Malhado é um espaço de resistência dos mercados tradicionais, mas a sua sobrevivência dependerá de ações urgentes que deverão ser tomadas prioritariamente no âmbito das políticas e projetos públicos, já que a administração é de responsabilidade da Prefeitura Municipal de Ilhéus Bahia - Brasil.
\end{abstract}

PALAVRAS-CHAVE: Mercados Tradicionais; Feiras; Consumidores; Resistência; Brasil; Ilhéus.

\section{ABSTRACT}

Fairs for marketing of regional products in urban spaces are identified as sites of resistance and survival of markets faced with the expansion of supermarkets. They retain characteristics that attract consumers looking for good service, variety of products and services, mainly of regional products, although they do not offer the same standard of physical infrastructure, hygiene and cleanliness of supermarkets. In this context, this study presents the results of an exploratory research conducted with consumers of the Malhado Fair in the year of 2014, in the city of Ilhéus, state of Bahia, Brazil, and the analysis of its SWOT strategic environment, strengths, weaknesses (internal environment of the organization), opportunities and threats of the macroenvironment. The obtained results showed that the Malhado Fair is a space of resistance from traditional markets, but its survival depends on urgent actions, which should be taken as a priority in the context of policies and public projects, since its administration is the responsibility of the City Hall of Ilhéus.

KEYWORDS: Traditional Markets; Fairs; Consumers; Resistance; Brazil; Ilhéus. 


\section{Introdução}

A existência dos mercados tradicionais como as feiras, para a compra e venda de produtos é identificada desde o início das atividades comerciais da humanidade quando os produtores rurais e as tropas de gado se deslocavam para as cidades ou aglomerados urbanos com o objetivo de comercializar os itens de subsistência (alimentos, carnes, roupas, entre outros).

O ambiente de comercialização em espaço aberto que propicia o encontro de pessoas de diversas classes sociais e agrupa grande variedade de produtos para comercialização é muito mais do que um simples mercado. Pode ser caracterizado como um espaço de resistência se for considerada a expansão dos grandes supermercados e também um local onde as pessoas interagem com maior intensidade com outros consumidores e também com os comerciantes.

Esse espaço que propicia a exploração dos 5 (cinco) sentidos (olfato, tato, paladar, audição e visão) dos consumidores (KINJO; IKEDA, 2005) resiste com a sobrevivência nos espaços urbanos, ocupa o papel de integração de pessoas, mercado de variedades e de preços atrativos, mas também sofre ameaças no contexto de maior exigência dos consumidores com relação a qualidade dos produtos e serviços e a diversidade de produtos e serviços ofertados pelos supermercados.

Nas cidades brasileiras de médio e pequeno, principalmente nas cidades da região Norte e Nordeste do Brasil, as feiras e centrais de abastecimento exercem papel importante como centros de comercialização de produtos perecíveis como carnes, pescados, hortifrutigranjeiros e produtos tradicionais (farinha, tapioca, condimentos, ervas, etc). Nesses espaços os moradores de cidades do entorno de regiões metropolitanas e cidades consideradas como abastecedoras, deslocam-se periodicamente (semanalmente ou mensalmente) para a realização das compras para subsistência de suas famílias, com a perspectiva de obterem no espaço das feiras a oferta de variedade de produtos e melhores preços (GALDINO DANTAS, 2008).

Foi identificada na cidade de llhéus - Bahia - Brasil a existência de um mercado tradicional conhecido popularmente como "Feira do Malhado" que há mais de 30 (trinta) anos é um espaço de comercialização de carnes, pescados, hortifrutigranjeiros, produtos tradicionais do Estado da Bahia (ervas, tapioca, farinha, condimentos, etc), artigos de artesanato, confecções, entre outros.

A Feira do Malhado de llhéus pode ser considerada como um lócus de resistência dos mercados tradicionais frente à expansão dos mercados convencionais, de acordo com termo atribuído por Galdino Dantas (2008).

Mesmo com a agregação da má reputação do bairro no qual está localizada a Feira do Malhado de Ilhéus; (associado ao tráfico de drogas, ausência de saneamento e violência), divulgada nas mídias televisivas e redes sociais da internet, a feira é o espaço comercial da cidade que recebe o maior número de clientes por dia: 5.000 pessoas entre moradores regionais e turistas na baixa temporada (período de abril à novembro) e 11.000 (período de dezembro à março) na alta temporada (ESTIVAL; BEHRMANN; RUSCIOLELLI, 2014). É também classificada como um mercado de atrativo cultural de Ilhéus conforme o Inventário Turístico do Município de Ilhéus (ISUS, 2015). Apesar da classificação e da identificação do aumento do fluxo de pessoas diariamente no período da alta temporada do turismo na cidade de 
Ilhéus (aumento de 5.000 pessoas para 11.000), não foi identificada a inserção do roteiro de visita à feira entre os guias e agências de turismo locais. As precárias condições das instalações físicas e exposição à violência são fatores sinalizados como motivadores para a não inclusão formal nos roteiros de visitas aos pontos turísticos da cidade.

Frente ao contexto apresentado foi justificada a relevância para a realização de uma pesquisa com o objetivo de aprofundar as informações sobre o diagnóstico mercadológico da Feira do Malhado e conhecer o grau de satisfação e as percepções dos consumidores sobre os produtos, serviços e o espaço de comercialização.

O objetivo geral do presente artigo é apresentar uma análise crítica da pesquisa de mercado realizada junto aos consumidores da Feira do Malhado no ano de 2014 na cidade de Ilhéus, Bahia, Brasil, com a utilização da ferramenta de análise de ambiente: SWOT, que mede as forças ( $\mathrm{S}$, de stregths) fraquezas (W, de weakenesses) do microambiente do negócio, assim como oportunidades $(\mathrm{O}$, de opportunities) e ameaças ( $T$, de threats) do macroambiente - fatores externos (ENDEAVOR, 2015), com a inclusão das propostas de melhorias com o objetivo de subsidiar a implantação de políticas públicas, programas e projetos.

\section{Nercados tradicionais: as feiras como espaços de resistência}

A palavra latina feria, que deu origem à portuguesa feira, significa dia santo, feriado. As primeiras feiras no Brasil foram realizadas em 1904 na cidade do Rio de Janeiro e em 1914 na cidade de São Paulo no Brasil.

De acordo com Harvey (1981, p.207) "o mercado de troca existia desde os tempos remotos e as primeiras cidades foram, entre outras coisas, os locais onde essa atividade estava provavelmente concentrada". Configuram-se até os dias atuais como espaços para comercialização dos excedentes dos produtos agrícolas e tradicionais.

As feiras podem ser caracterizadas como elementos da cultura popular, mesmo configurando-se com caráter comercial, pois preservam as tradições, a troca de conhecimentos, a possibilidade do espaço para a integração social e a relação de confiança no valor e qualidade dos produtos e serviços. Enfrentam riscos para sobrevivência na contemporaneidade devido à alta competição do comércio, principalmente no cenário da expansão dos supermercados e quando a supervisão do poder público não ocorre ou é realizada de uma forma que exclui suas características fundamentais (GUIMARÃES, 2010).

Para Galdino Dantas (p.99, 2008), "é possível afirmar que as feiras estão enraizadas no espaço urbano das cidades e são um espaço de resistência as mudanças das estruturas de comercialização, distribuição e consumo".

De acordo com (Mascarenhas, 2008, p.83) a feira livre é a "filha rebelde da modernidade, que insiste em desafiá-la" e ocupa espaços definitivos nas cidades.

As feiras urbanas podem ser caracterizadas como um espaço de trocas comerciais, interação social, encontros e socialização. Também oferecem as pessoas oportunidades de trabalho com características particulares com relação aos empregos convencionais. Mesmo com as transformações do mundo do trabalho multiplicam-se 0 número de vendedores ambulantes de frutas, verduras, artesanatos, produtos "importados", floristas, etc. Nesse mercado caracterizado 
como informal pela Organização Internacional do Trabalho (OIT), os feirantes são em geral empreendedores do próprio negócio e atuam em estruturas familiares (BUSSO; GORDAN, 2003).

Outra característica importante das feiras é a ocorrência em espaços públicos que envolvem em geral pouca necessidade de capital (máquinas e tecnologias), possuem flexibilidade para mudanças, diversificações e podem se desenvolver em pontos fixos ou semi fixos. As feiras ainda podem ser encontradas em qualquer lugar do mundo contemporâneo e fazem parte da identidade regional, local, onde se manifestam as cores, aromas, músicas, produtos, pessoas e diferentes culturas características de uma região (BUSSO, 2010).

Para Sacco dos Anjos et. al., (2005 apud PIERRI; VALENTE, 2010) a resistência das feiras indica que além dos aspectos econômicos existe a predominância dos aspectos culturais e simbólicos da feira livre na mentalidade dos consumidores. Não representam somente um sistema local de comercialização, mas englobam também as tradições regionais, pois guardam aspectos culturais marcantes da cidade, com o exercício de protagonismo social e cultural.

Além de ser considerado como um espaço de resistência dos mercados tradicionais nos centros urbanos, as feiras também são espaços nos quais 0 comportamento dos consumidores apresenta diferenças com relação as expressões nos mercados tradicionais, como os supermercados.

O trabalho realizado por (KINJO; IKEDA, 2005) estudou o comportamento dos consumidores em feiras livres e os dados obtidos indicaram que $56 \%$ dos entrevistados efetuam compras nesses locais porque acreditam na qualidade dos produtos e este critério é considerado como o fator decisivo para a compra dos produtos nas feiras. Dos consumidores entrevistados, $28 \%$ consideraram o preço mais vantajoso em relação aos mercados.

Os pesquisadores identificaram também que a feira apresenta na percepção dos consumidores vantagem em relação aos hipermercados e outros estabelecimentos por oferecer variedade de frutas, verduras, legumes, peixes e outros produtos de boa qualidade semanalmente. Mesmo com a oferta de promoções e variedade nos hipermercados é na feira que as pessoas procuram e encontra qualidade e variedade. A informação que confirma essa percepção de acordo com a pesquisa é a avaliação de $68 \%$ dos consumidores entrevistados que consideraram os produtos vendidos em feiras como de qualidade superior (KINJO; IKEDA, 2005).

\section{Metodologia}

Como metodologia foram utilizadas a pesquisa bibliográfica, documental e em meios eletrônicos no período de abril a junho de 2014 com o objetivo de analisar o estado da arte sobre os mercados tradicionais e feiras no Brasil e conhecer o contexto e a história da Feira do Malhado em Ilhéus - Bahia - Brasil.

Como uma pesquisa social aplicada o trabalho desenvolvido é classificado como pesquisa exploratória, construído com o objetivo de proporcionar uma visão geral sobre um determinado fato (GIL, 2010), nesse contexto o foco foi obter uma visão geral do mercado consumidor da feira do Malhado em llhéus, Estado da Bahia. Situação que foi possível ser constatada através da pesquisa bibliográfica e 
documental realizada na etapa prévia à pesquisa exploratória com o objetivo de identificar publicações científicas em periódicos nacionais que abordassem os mercados tradicionais, feiras e informações sobre a Feira do Malhado de llhéus.

Para o levantamento das informações sobre as percepções dos consumidores da feira foi realizada uma pesquisa de campo entre os meses de abril e maio de 2014 onde as informações foram coletadas através de entrevistas diretas com a utilização de questionários semiestruturados.

Os questionários semiestruturados englobaram questões fechadas e abertas com a finalidade de avaliar o grau de satisfação, percepções e sugestões dos consumidores da Feira do Malhado no ato da compra e no ambiente comercial da feira.

Para a definição da amostra da pesquisa foi escolhida a amostragem intencional não probabilística, que consistiu em selecionar um subgrupo da população que possa ser representativo de toda a população, com base em orientações de profissionais com experiência na área de estudo (GIL, 2010).

Como a feira é subdividida em 4 (quatro) setores: (hortifrutigranjeiros, carnes e pescados, confecções, bares e restaurantes) os pesquisadores foram deslocados para aplicação dos questionários e realização das entrevistas no espaço da feira, nos dias de maior fluxo de consumidores (aos sábados) onde realizaram a aplicação de 50 (cinquenta) questionários por setor, totalizando 200 (duzentos) entrevistados.

Para agregar informações sobre as percepções dos consumidores foi utilizada também a pesquisa netnográfica no site Foursquare (FOURSQUARE, 2015). A pesquisa netnográfica de acordo com Kozinets (2010, p.61 e 62) é uma pesquisa de observação baseada no trabalho de campo on line, onde são utilizadas comunicações através do computador como fonte de dados para se atingir a compreensão de um fenômeno cultural.

Para a análise das informações da pesquisa foi utilizada a matriz estratégica SWOT, conhecida no Brasil como Matriz FOFA, ela mede as forças ( $\mathrm{S}$, de stregths) fraquezas (W, de weakenesses) do negócio - fatores internos - assim como oportunidades $(\mathrm{O}$, de opportunities) e ameaças ( $\mathrm{T}$, de threats) do macroambiente fatores externos (ENDEAVOR, 2015).

\section{A Feira do Malhado em Ilhéus - Bahia - Brasil}

A cidade de Ilhéus localizada no Litoral Sul da Bahia, na região Nordeste do Brasil, possui uma população estimada em 184.236 mil habitantes, dentre os quais, 89.440 homens e 94.796 mulheres (IBGE, 2010). A distribuição por faixa etária evidencia que a maioria da população concentra-se na faixa de 18 a 50 anos. $O$ município possui 61 escolas para o nível fundamental e 16 para o nível médio, no entanto ainda amarga uma taxa de 12,49 por cento de analfabetismo (INSTITUTO NOSSA ILHÉUS, 2010).

Os dados quanto ao emprego e renda evidenciam que o município possui grandes contrastes socioeconômicos: 9,26 \% vivem em Estado de extrema pobreza, ou vivem com aproximadamente $\mathrm{R} \$ 70,00$ reais por pessoa; $18,36 \%$ vivem com a renda per capta de $1 / 4$ do salário mínimo. Na análise por unidade familiar, verifica-se que $14,61 \%$ de domicílios vivem com $1 / 4$ do salário mínimo e 38,14\% de domicílios vivem com apenas $1 / 2$ salario mínimo. Quanto à moradia, registra-se $21,26 \%$ vivendo 
em aglomerados subnormais e $34,21 \%$ dos domicílios sem esgoto encanado. $\mathrm{Na}$ zona rural, a ausência de esgoto encanado sobe para 68,12\% (INSTITUTO NOSSA ILHÉUS, 2010).

Mesmo com indicadores precisando melhorar e muito, llhéus ainda é considerada "A Princesinha do Sul", "A Capital do Cacau" e o "Berço de Jorge Amado", sendo o eterno cenário de "Gabriela, Cravo e Canela". Com um patrimônio ambiental fantástico, uma beleza incomparável, e $93 \mathrm{~km}$ de praias exuberantes. De fato, esse potencial existe, como registrado em projetos locais, além da vasta literatura enobrecedora deste local, como se depreende do trecho abaixo:

Dada à extensão do município e a sua diversidade de biossistemas, representados por ecossistemas marinhos costeiros, mata atlântica e ecossistemas associados a exemplo de mangue e restinga; bacias hidrográficas; lagoas; cachoeiras; mata ciliar e encostas que juntos e harmoniosamente dão ao município um destaque de rara beleza, coloca-o como um dos maiores potenciais bióticos e cênicos da costa brasileira (PROJETO ORLA DE ILHÉUS, 2007: p. 22).

De acordo o a análise de Corrêa (2013), houve um significativo incremento turístico na Costa do Cacau nos últimos 15 anos, o qual tem a natureza como principal vetor desse segmento. As Unidades Hoteleiras (UH) evoluíram na última década de 3.343 para 4.139. Itacaré passou de $732 \mathrm{UH}$ em 2001 para $1.142 \mathrm{em}$ 2006, sendo que a maioria dessas unidades se encontra no Litoral Sul. O Litoral Norte está em fase de crescimento, conta $8 \%$ do total do município (BAHIATURSA, 2008). Conforme dados da BAHIATURSA (2008), a implantação de mais 903 unidades hoteleiras entre llhéus e Itacaré estão previstos, o qual totaliza um investimento da ordem de $\mathrm{R} \$ 430.707 .000,00$. Dentre estas, 103 serão implantadas na costa de Itacaré e 544 no Litoral Norte de llhéus, que conta ainda, com $70 \%$ de suas áreas naturais preservadas. Estima-se que a instalação dessas unidades hoteleiras irá gerar em torno de 28.204 empregos, entre os quais 7.879 serão empregos diretos e 20.325 empregos indiretos, gerando um PIB de atividades ligadas ao turismo da ordem de 23,3\%, conforme relatório do Plano de Desenvolvimento Integrado do Turismo Sustentável do Pólo Litoral Sul (PDITS Polo Litoral Sul). Essas previsões demonstram que a manutenção do ativo ambiental como matéria-prima essencial e como um produto para o turismo é uma alternativa viável, assegurando para o futuro a qualidade ambiental, paisagística e social dessa região).

$\mathrm{Na}$ visão de Corrêa (2013), medidas para alavancar o turismo devem ser implementadas, principalmente em relação à infraestrutura básica de esgotamento sanitário e a mão de obra qualificada para receber os turistas. As deficiências nesses dois itens de infraestrutura e qualificação refletem negativamente nos serviços turísticos atuais, requerendo soluções. É importante destacar as condições naturais que favorecem o turismo histórico e ecológico nas fazendas de cacau.

Nessa abordagem, apenas se focou no turismo como uma realidade socioeconômica em llhéus. No entanto, sua sustentabilidade vem sendo discutida, uma vez que a degradação ambiental também acontece com a atividade turística, sendo necessárias estratégias que visem a sustentabilidade local, onde a comunidade "seja o principal agente transformador" (SOUZA, 2005: p.45). O turismo 
é apresentado pela autora como alternativa sustentável, ao incluir a participação das comunidades locais como participantes ativas neste processo, de forma que 0 turismo seja um processo includente, necessitando para tanto de um programa de educação ambiental, com o fim de conscientizar a comunidade local e os turistas sobre hábitos ambientalmente corretos.

O turismo em Ilhéus aconteceu como uma alternativa de renda no contexto do declínio da cultura do cacau. Sendo assim, está sendo desenvolvido de forma amadora, sem atender adequadamente as normas exigentes para a realização dessa atividade (NOIA, 2008). Para que o turismo aconteça de forma sustentável, é necessário equilíbrio entre comunidade, turista, governo e meio ambiente. Em Ilhéus o turismo é realizado de forma profissional há pouco tempo, mais ou menos 22 anos (NOIA, 2008).

De acordo com o inventário turístico do município de Ilhéus (ISUS, 2012), projeto considerado referência e pioneiro, realizado pelo Ministério do Turismo do Brasil, a Feira do Malhado é classificada como um mercado de atrativo cultural de Ilhéus. Localizada no bairro do Malhado, a Feira do Malhado de Ilhéus ou Central de Abastecimento do Malhado é administrada pela Prefeitura Municipal de Ilhéus e foi fundada no ano de 1980. Possui fluxo diário de clientes de 5.000 pessoas na baixa temporada (março à novembro) e 11.000 pessoas na alta temporada (dezembro à fevereiro).

A estrutura da feira é subdividida em pontos fixos e móveis de vendas; são 1.768 pontos fixos, onde cada feirante paga uma mensalidade média de $R \$ 20,00$ por mês referente a locação do espaço e 932 pontos móveis, conhecidos como "feirantes da lona" que realizam o comércio de hortifrutigranjeiros em cima de lonas de plástico na calçada externa do espaço de comercialização (ESTIVAL; BEHRMANN; RUSCIOCELLI, 2014).

A Feira do Malhado de Ilhéus, Bahia, Brasil, está localizada no bairro do Malhado ao qual foi atribuído o maior índice de homicídios entre os anos de 2007 à 2009 (7 COORPIN ILHÉUS, 2009 apud GUIRRA et al. 2010).

Quando é realizada a busca através de palavras-chaves no site Google (GOOGLE, 2015), no link sobre imagens bairro do malhado Ilhéus foram encontradas fotos que remetem em grande parte a ausência de saneamento, violência, tráfico de drogas, lixo em vias públicas.

\section{Diagnóstico mercadológico da Feira do Malhado: quais as percepções dos consumidores?}

A partir da pesquisa netnográfica realizada a partir de consulta as informações disponíveis no site Foursquare (FOURSQUARE, 2015). O Foursquare é um site no formato de uma plataforma colaborativa digital onde são disponibilizadas informações e avaliações realizadas por consumidores e visitantes sobre mais de 75 milhões de estabelecimentos no Mundo (FOURSQUARE, 2015).

Através da busca aos termos Central de Abastecimento do Malhado em Ilhéus Bahia ou Mercado de Pulgas em Ilhéus no site Foursquare, foi possível identificar que 644 pessoas estiveram no local até o dia 14 de abril de 2015 e realizaram a confirmação através do site e 2.172 pessoas buscaram informações sobre o local (Figura 1). 


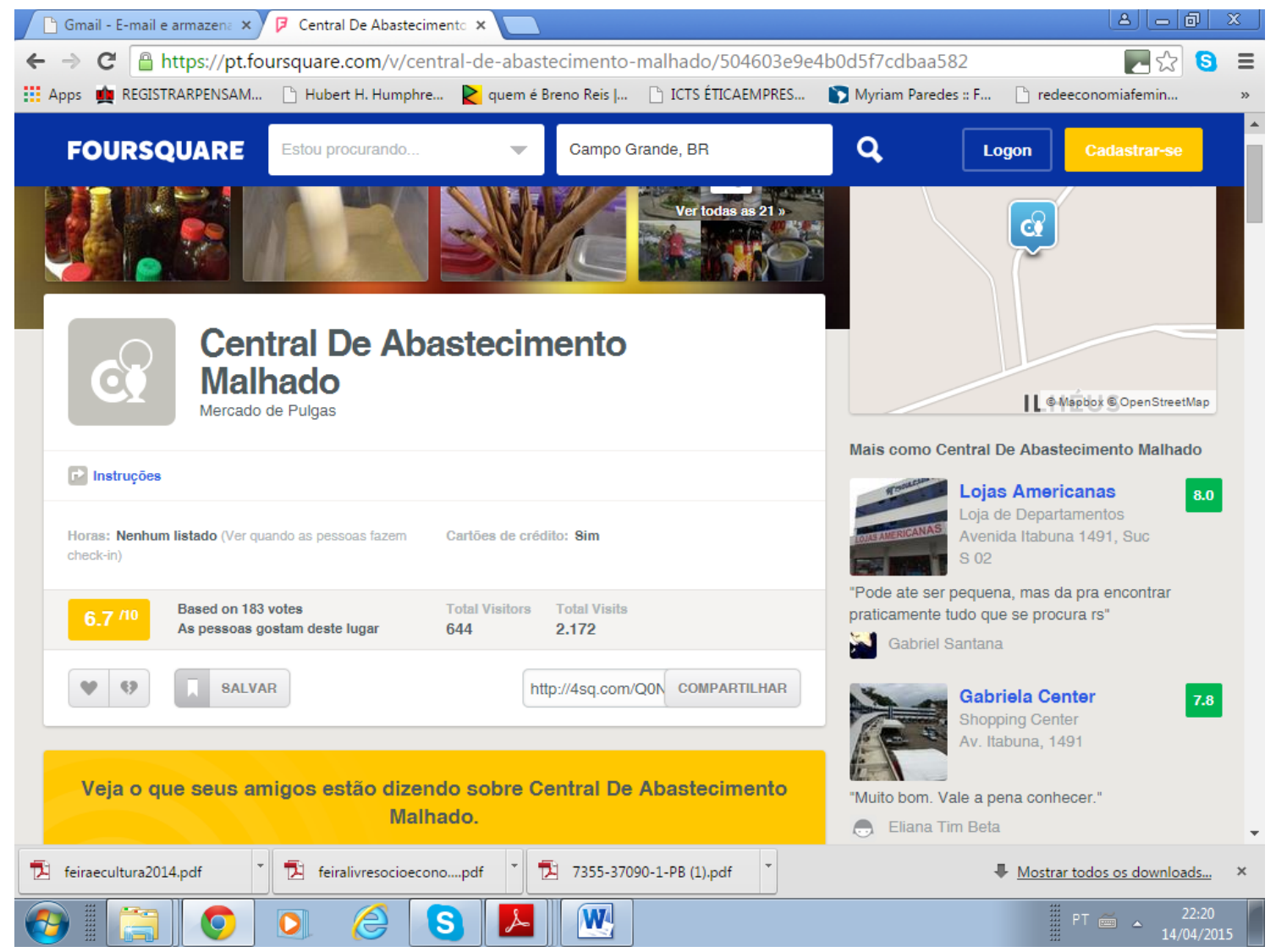

Figura 1: Imagem das informações gerais sobre a Central de Abastecimento do Malhado em llhéus a partir do site Foursquare. Fonte: Foursquare (2015).

Figure 1: Image of general information about the Central de Abastecimento do Malhado in Ilheus from Foursquare website. Source: Foursquare (2015).

O site oferece a opção do visitante do local que realizou o chamado check in ou confirmação da visita presencial ao estabelecimento, nesse caso a Central de Abastecimento do Malhado ou Feira do Malhado de llhéus, atribuir uma nota para avaliação de 0 (ruim) à 10 (excelente). A avaliação média dos visitantes atingiu a nota 6,7 em 14 de abril de 2015, com base em 183 votos realizados entre os frequentadores.

Entre os principais comentários expressos pelos visitantes destacaram-se os seguintes apresentados na Figura 2 a seguir: 


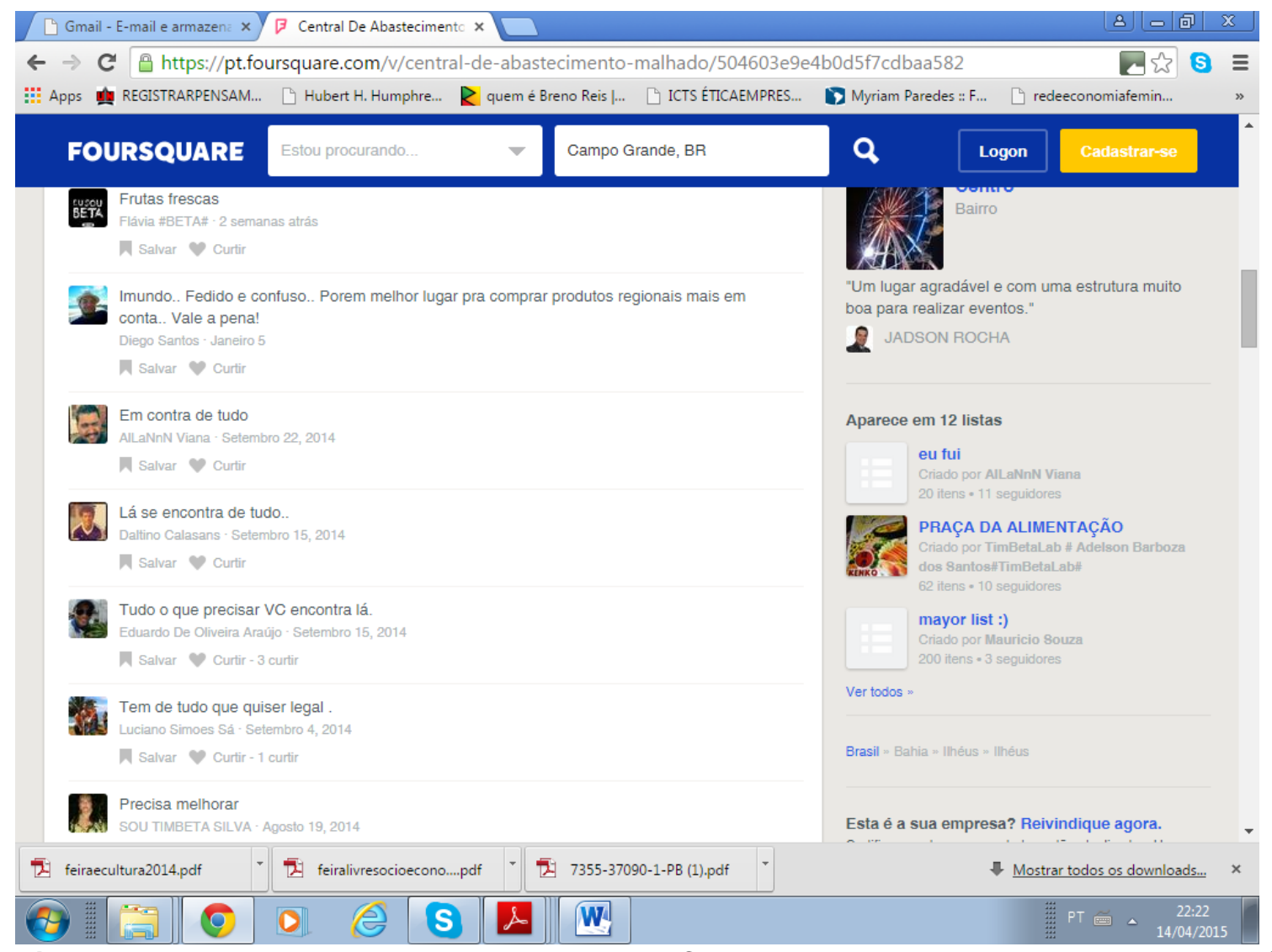

Figura 2: Avaliações qualitativas dos visitantes da Central de Abastecimento do Malhado em llhéus. Fonte: Foursquare (2015).

Figure 2: Qualitative assessments of Central de Abastecimento do Malhado visitors in Ilheus. Source: Foursquare (2015).

Com base na pesquisa netnográfica as conclusões parciais foram que a Central de Abastecimento do Malhado é um espaço de resistência na cidade, se constitui como parte da tradição regional, apresenta traços da cultura regional, é um espaço de comercialização com variedade de produtos e bons preços, mas possui problemas graves: ausência de saneamento, sujeira, vulnerabilidade da segurança e descaso do poder público, nesse caso da Prefeitura Municipal de llhéus, que é o órgão responsável pela administração do local.

A partir da pesquisa exploratória realizada entre abril e maio de 2014 através de entrevistas diretas junto a 200 (duzentos) consumidores que frequentam a Feira do Malhado foi possível identificar que o espaço de comercialização é dividido entre os segmentos: bares e lanchonetes, confecções, hortifruti, pescados e carnes.

Através dos resultados das entrevistas diretas junto aos grupos de consumidores de cada um dos segmentos da feira do Malhado, no local de compra, foi possível identificar as suas percepções e avaliações sobre aspectos do processo de consumo referentes a variedade, atendimento, segurança, instalações físicas, estacionamento, higiene, limpeza e localização.

Com relação a avaliação sobre a variedade dos produtos e serviços oferecidos na Feira do Malhado, a Figura 3 a seguir apresenta o panorama geral. 


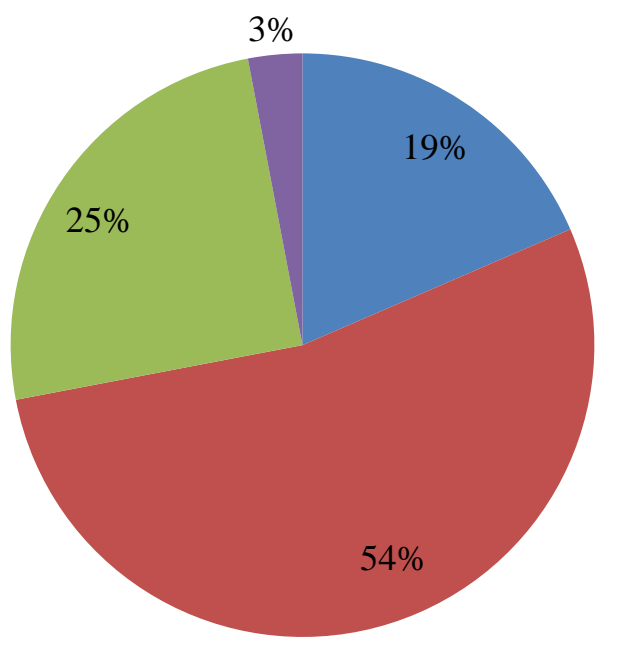

Excelente

Boa

negular

nuim

Figura 3: Avaliação dos consumidores da Feira do Malhado sobre a variedade dos produtos e serviços. Fonte: dados da pesquisa (2015).

Figure 3: Consumer Assessment of Feira do Malhado on the variety of products and services.

Source: research data (2015).

Dos 200 (duzentos) consumidores entrevistados, 54\% avaliaram a variedade dos produtos e serviços como boa e $19 \%$ como excelente, $25 \%$ como regular e apenas 3\% como ruim. A avaliação sobre a percepção do consumidor da feira com relação a consideração de que é um espaço que oferece boa variedade de produtos e serviços está alinhada aos resultados da pesquisa realizada em feiras do Brasil por Kinjo e Ikeda (2005).

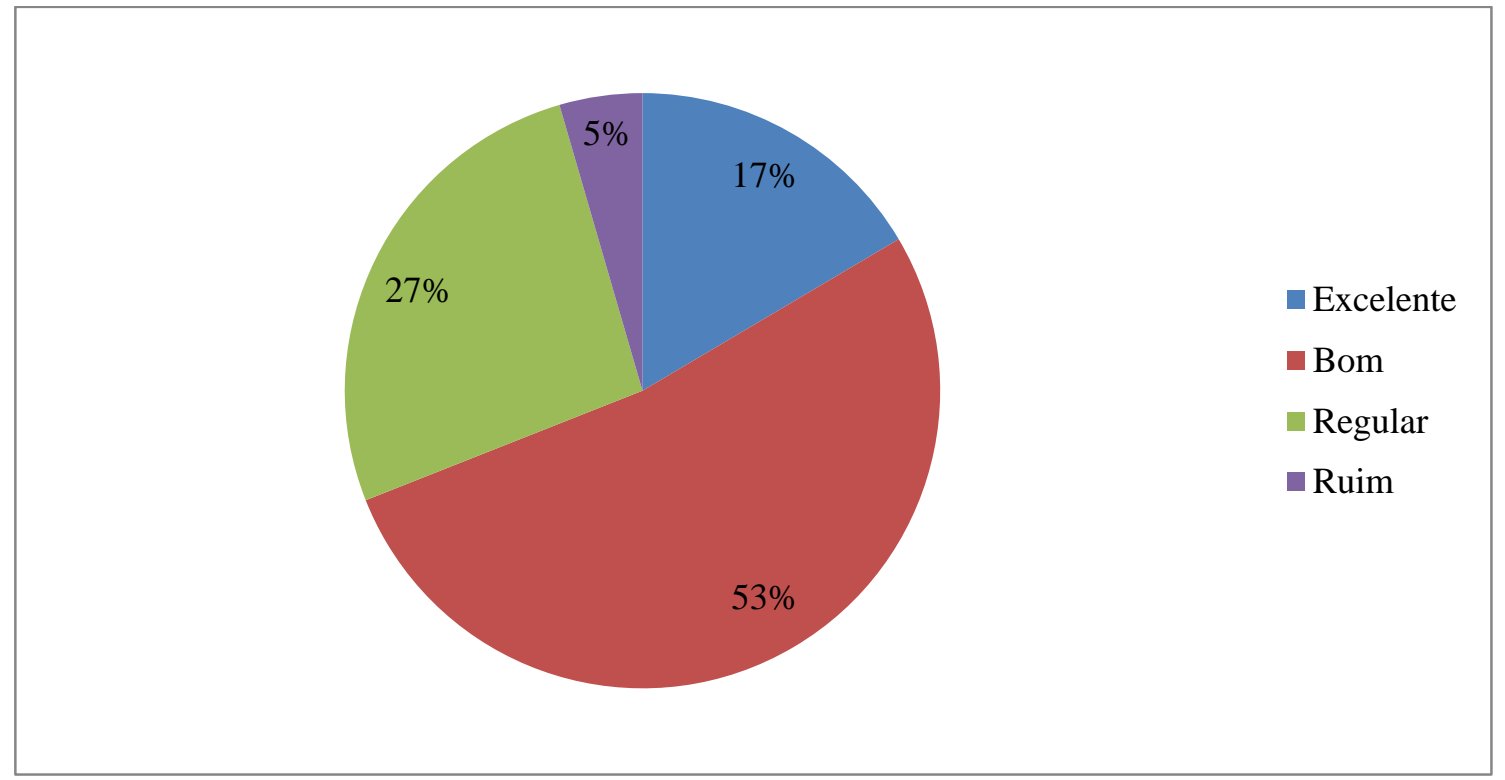

Figura 4: Avaliação dos consumidores da Feira do Malhado sobre o atendimento. Fonte: dados da pesquisa (2015).

Figure 4: Consumer Assessment of Feira do Malhado on the service.

Source: research data (2015). 
Sobre o atendimento no espaço da feira, de acordo com a Figura 4 acima, $17 \%$ dos entrevistados avaliaram como excelente e $53 \%$ como bom, $27 \%$ como regular e apenas 5\% como ruim. Os dados obtidos na avaliação do atendimento também estão alinhados aos resultados obtidos na avaliação do atendimento dos consumidores de feiras por Kinjo e Ikeda (2005), onde 78\% dos entrevistados consideraram o atendimento no espaço das feiras entre bom e excelente.

A segurança oferecida e percebida pelos consumidores no espaço da Feira do Malhado como apresenta a Figura 5, foi avaliada como ruim por $67 \%$ dos entrevistados e regular para $24 \%$. Trata-se de um dos fatores críticos na perspectiva da avaliação dos consumidores, que influenciam a decisão de frequentar ou não o espaço para a comercialização. Como discutido anteriormente, o bairro do Malhado, em Ilhéus, Bahia, onde está localizada a feira, é uma região com altos índices de violência e tráfico de drogas, situação que com ausência de ação da esfera pública municipal, é agravada e se reflete de forma negativa na falta de segurança nos espaços de comercialização

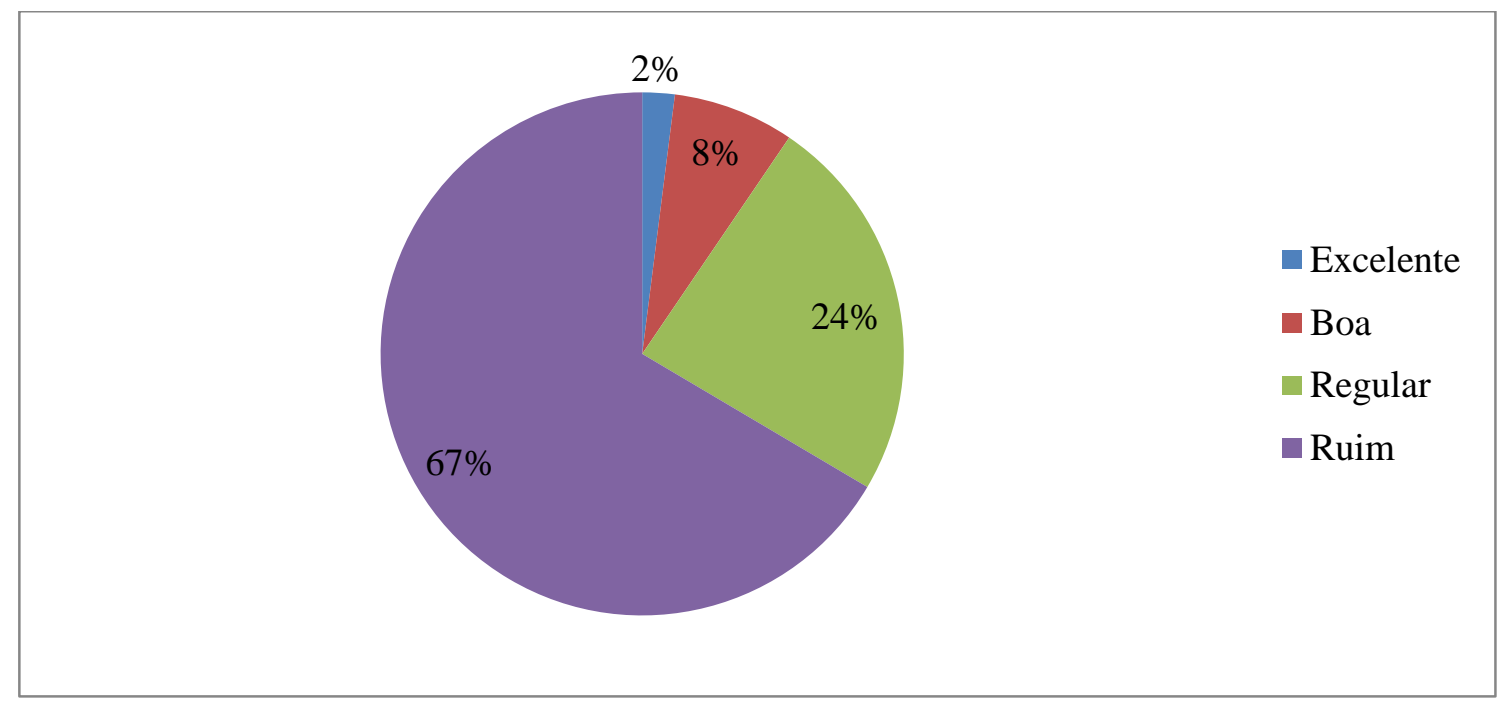

Figura 5: Avaliação dos consumidores sobre a segurança no espaço da feira.

Fonte: dados da pesquisa (2015).

Figure 5: Consumer Assessment of safety within the fair. Source: research data (2015)

A Figura 6 reforça que as instalações físicas também se constituem como um ponto classificado como negativo sob as perspectivas dos consumidores na avaliação da feira. Dos consumidores entrevistados, 55\% avaliaram as instalações físicas como ruins e $31 \%$ como regulares, somente $1 \%$ considerou excelente e $14 \%$ como boas. No ano de 2013 o Governo do Estado da Bahia, através da Companhia de Ação para o Desenvolvimento Regional (CAR), aprovou o projeto de revitalização da Feira do Malhado, com execução prevista para o ano de 2014. Até o momento da finalização do presente trabalho no mês de junho de 2015 não havia previsão para o início do projeto proposto. 


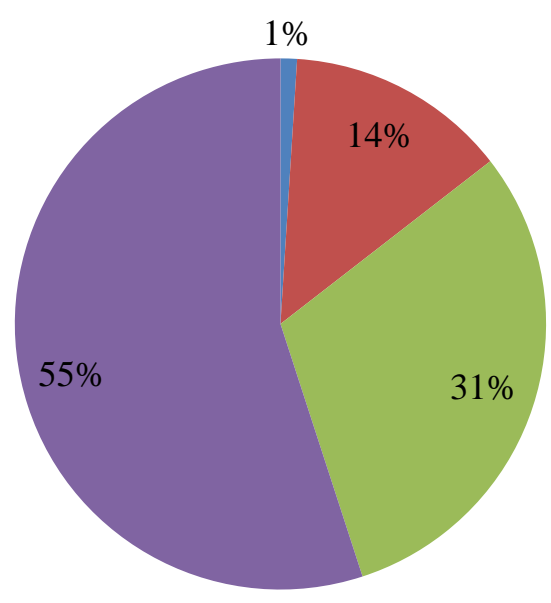

Excelente

Boa

- Regular

- Ruim

Figura 6: Avaliação das instalações físicas do espaço da feira. Fonte: dados da pesquisa (2015). Figure 6: Evaluation of the physical facilities of the show floor. Source: research data (2015).

A Figura 7 apresenta os resultados das avaliações sobre o espaço para o estacionamento de veículos e acesso a feira. Para $77 \%$ dos entrevistados as condições do espaço do estacionamento podem ser classificadas entre ruins e regulares, trata-se de um gargalo para a acessibilidade nos espaços de comercialização da feira, pois devido aos problemas da falta de segurança e saneamento (quando há chuvas as áreas de acesso ficam alagadas, inviabilizando o acesso a pé dos consumidores), há ausência de condições adequadas influenciam diretamente a opção de se deslocar ou não para a compra no local.

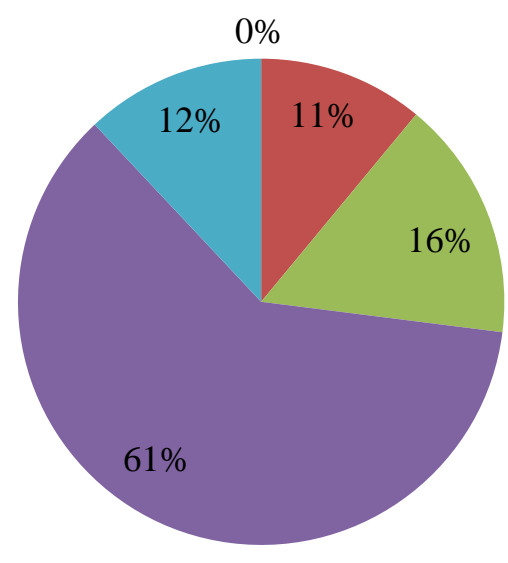

Excelente

Bom

Regular

Ruim

não informou

Figura 7: Avaliação do espaço do estacionamento de veículos da feira.

Fonte: dados da pesquisa (2015).

Figure 7: Parking space evaluation of the fair vehicles.

Source: research data (2015) 
De acordo com a Figura 8 os aspectos referentes a ausência de condições mínimas de higiene, limpeza e organização dos espaços de comercialização são os pontos críticos, que demandam ações urgentes na percepção de $94 \%$ dos entrevistados. Apenas $6 \%$ consideraram essas condições como boas e nenhum como excelente. Pode-se inferir através da análise dos resultados que esses fatores seriam os maiores influenciadores pela opção dos consumidores em migrarem para outros espaços de consumo, como os supermercados, por exemplo, em busca de condições mais adequadas para a compra e consumo de alimentos seguros, ambiente com condições mínimas de acessibilidade e conforto para o processo de compra.

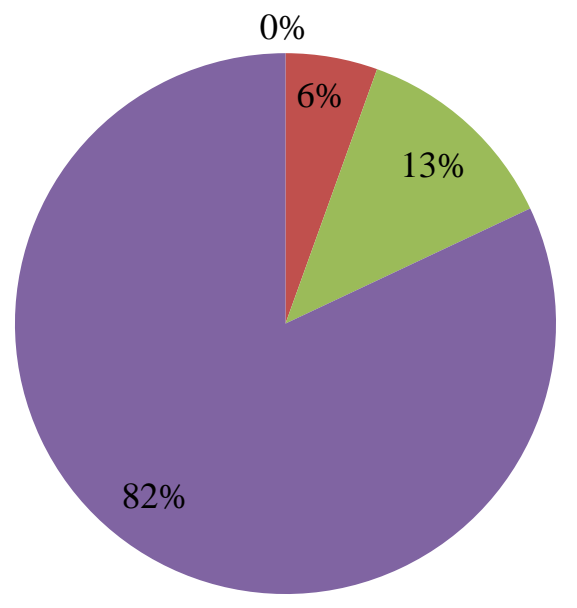

Excelente

Boa

Regular

Ruim

Figura 8: Avaliação da higiene, limpeza e organização do espaço da feira.

Fonte: dados da pesquisa (2015).

Figure 8: Hygiene Evaluation, cleaning and organization of the show floor.

Source: research data (2015)

As principais sugestões apresentadas pelos consumidores, quando indagados sobre o que apresentariam como sugestões de melhorias para a Feira do Malhado foram as seguintes:

-Melhoria da limpeza e higiene;

-Melhoria da organização;

-Melhoria da segurança com aumento do policiamento no local;

-Melhoria da gestão da Feira do Malhado, administrada pela Prefeitura Municipal de Ilhéus;

-Atuação efetiva e transparente do setor público;

-Cooperação entre os feirantes;

-Qualificação da mão de obra;

-Melhoria na infraestrutura (desobstrução das vias de acesso, construção de pisos, criação de boxes, necessidade de escoamento da água da chuva, melhoria do saneamento básico, melhoria das instalações, instalação de banheiros, padronização dos boxes, criação de setores, 
alocação de lixeiras, construção de cobertura, criação de estacionamento, melhoria na área conhecida como "Malvina" - área localizada no espaço da feira do Malhado onde há traficantes e usuários de drogas em concorrência do espaço com os consumidores e feirantes);

-Demolição e construção de nova feira.

A Figura 9 a seguir apresenta algumas visualizações do espaço de comercialização da Feira do Malhado.

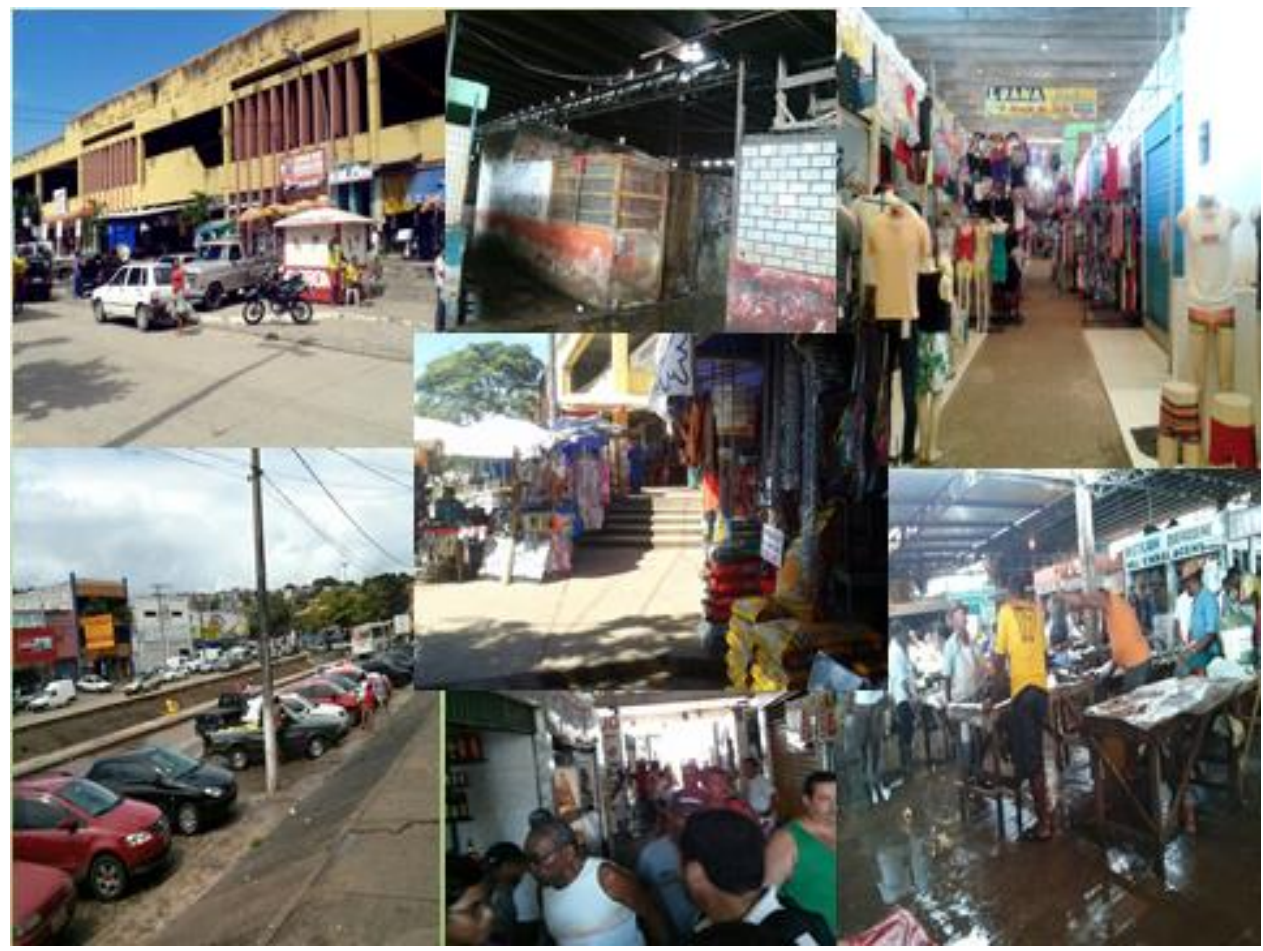

Figura 9: Espaços de comercialização do ambiente da feira. Fonte: dados da pesquisa (2015).

Figure 9: Exhibition of environmental marketing spaces. Source: research data (2015).

\section{Análise SWOT e propostas de melhorias}

De acordo com Oliveira (2007) as metodologias de análise do ambiente são compostas por ferramentas de captação, organização e análise de variáveis para a análise de um determinado ambiente organizacional ou mercadológico e apesar de serem mais utilizadas nos ambientes das organizações corporativas, apresentam-se como importantes metodologias para análises de outros contextos, nos cenários do planejamento e avaliação de organizações públicas e terceiro setor.

No âmbito do planejamento estratégico uma importante ferramenta de análise tem se destacado, a matriz SWOT ${ }^{1}$, consiste em um instrumento de fácil utilização que possibilita identificar a posição estratégica da organização através do diagnóstico de ambientes.

Essa metodologia apresenta-se de forma ideal ao processo de gestão e monitoramento de projetos, podendo pode ser aplicada a uma nação, região, território, indústria, empreendimento ou empresa. Sua utilização direciona-se as ações do planejamento estratégico, verificando a situação da organização e suas condições de posicionamento no mercado. A partir do desenvolvimento de análises, 
essa ferramenta colabora para criação de estratégias competitivas, por meio da definição das fortalezas e fraquezas - inerentes ao ambiente interno, e oportunidades e ameaças - fatores externos (SILVEIRA, 2001).

$\mathrm{Na}$ análise interna são definidos os pontos fortes do empreendimento que podem ser trabalhados para buscar oportunidades ou para neutralizar ameaças futuras e os pontos fracos que fragilizam a unidade e que podem vir a ser objeto de ações estratégicas de estruturação e fortalecimento institucional. A análise é focada na unidade, com o intuito de examinar seus processos, capacidade e infraestruturas (CASTRO et al., 2005). Através da análise do ambiente interno é possível produzir vantagens competitivas aumentando suas forças potenciais, e diminuindo as fraquezas com estratégias significativas.

Quanto à análise ambiental externa, sua realização parte da identificação de sistemas ou grupos que influenciam a organização de forma direta ou indireta, ou que são influenciados pela mesma. Nessa etapa as mudanças e eventos futuros são identificados, na procura de oportunidades e/ou ameaças (CASTRO et al., 2005). O ambiente externo constitui as variáveis que não podem ser controladas pela organização, entretanto elas podem ser perceptíveis e investigadas para antecipar mudanças, com a finalidade de aproveitar melhor as oportunidades e de ter um menor impacto sobre as ameaças, na construção de um planejamento adequado que minimize os riscos.

De acordo com Hitt, Ireland e Hoskisson (2008), uma oportunidade é uma condição no ambiente geral que, se explora, ajuda a empresa a obter competitividade estratégica. Uma ameaça é uma condição do ambiente geral que pode impedir os esforços de uma empresa em obter competitividade estratégica.

Sob a perspectiva de Tifany e Peterson (2000), o cruzamento dos elementos que compõe as forças e oportunidades da matriz SWOT são responsáveis por proporcionar a alavancagem organizacional, ajudando-a a extrair o máximo de proveito das situações. Quando o cenário indica o encontro entre ameaças e forças, há presença de vulnerabilidade, onde os pontos fortes podem ser utilizados para amenizar as ameaças. No momento em que a organização não pode usufruir das oportunidades por conta de seus pontos fracos, observa-se a existência de restrição. Finalmente, o enfraquecimento da empresa aliado às ameaças externas amplia ainda mais as fragilidades, sendo indicativo de problema.

Diante disso, com base em dados da pesquisa realizada na Feira do Malhado localizada na cidade de Ilhéus - BA, foram identificadas as forças e fraquezas estudadas in loco, somadas às oportunidades e ameaças observadas no ambiente externo, para tal, aplicou-se a metodologia SWOT conforme pode ser visto no Quadro 1. 
Quadro 1: Matriz SWOT da Central de Abastecimento do Malhado.

Frame 1: Matriz SWOT of Central de Abastecimento do Malhado.

\begin{tabular}{|c|c|c|}
\hline & AJUDA & ATRAPALHA \\
\hline 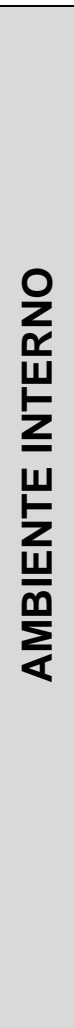 & $\begin{array}{l}\text { FORÇAS } \\
\text { Variedade de produtos e preços; } \\
\text { Produtos com tradição de comercialização; } \\
\text { Tradição do trabalho dos feirantes (mais de } 10 \\
\text { anos no local); } \\
\text { Trabalho familiar - transição entre gerações; } \\
\text { Bom nível de escolaridade; } \\
\text { Bom atendimento ao cliente; } \\
\text { Fidelização dos clientes; } \\
\text { Comercialização de produtos regionais; } \\
\text { Grande número de circulação de pessoas } \\
\text { diariamente - 5000 à 10.000; } \\
\text { Consumidores da região e turistas; } \\
\text { Abastece municípios do entorno; } \\
\text { Diversidade dos produtos ofertados; } \\
\text { Diversidade de classes sociais; } \\
\text { Crescimento do número de turistas interessados } \\
\text { no turismo cultural na região Sul da Bahia. }\end{array}$ & $\begin{array}{l}\text { 1.Falta de segurança; } \\
\text { 2.Falta de limpeza no ambiente interno e } \\
\text { externo; } \\
\text { 3.Desorganização do espaço físico; } \\
\text { 4.Falta de saneamento básico; } \\
\text { 5.Estacionamento limitado; } \\
\text { 6.Ausência de sinalização; } \\
\text { 7.Ausência de central de atendimento ao } \\
\text { turista/visitante; } \\
\text { 8.Inexistência de um site; } \\
\text { 9.Renda média inferior à } 2 \text { salários mínimos; } \\
\text { 10.Feirantes não trabalham de forma } \\
\text { coletiva; } \\
\text { 11."Monopólio" de alguns boxes com ações } \\
\text { que prejudicam o interesse coletivo; } \\
\text { 12.Trabalho infantil. }\end{array}$ \\
\hline 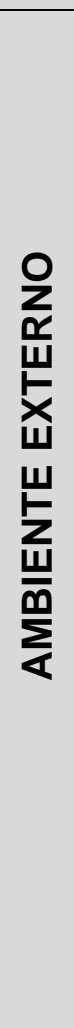 & $\begin{array}{l}\text { Consumidores buscam variedade de hortifrúti; } \\
\text { Busca pela saudabilidade na alimentação; } \\
\text { Interesse no consumo de produtos regionais; } \\
\text { Atendimento diferenciado - tendências do } \\
\text { comportamento do consumidor de feiras livres; } \\
\text { Valorização da cultura local no turismo; } \\
\text { Resistência dos mercados populares no Brasil; } \\
\text { A feira como espaço de lazer; } \\
\text { Economia solidária; } \\
\text { Feiras e mercados tradicionais como importantes } \\
\text { canais de comercialização dos produtos da } \\
\text { agricultura familiar; } \\
\text { Diversificação produtiva; } \\
\text { Centros de ensino da região; } \\
\text { Projeto de revitalização da CAR; } \\
\text { Crescimento do turismo cultural no Brasil; } \\
\text { Inventário Turístico de llhéus. }\end{array}$ & $\begin{array}{l}\text { 1.Precariedade do saneamento básico na } \\
\text { região; } \\
\text { 2.Altos índices de violência da região do } \\
\text { Malhado; } \\
\text { 3.Preconceitos e má reputação do bairro do } \\
\text { Malhado; } \\
\text { 4.Indefinição de roteiros que valorizem o } \\
\text { turismo tradicional nos mercados populares } \\
\text { da região; } \\
\text { 5.Crescimento comércio (supermercados, } \\
\text { atacados, bares, lanchonetes) na região de } \\
\text { entorno; } \\
\text { 6.Continuidade das famílias na atividade. }\end{array}$ \\
\hline
\end{tabular}

Fonte: Elaboração dos autores base em dados da pesquisa (2015).

Source: Prepared by the authors based on survey data (2015). 


\section{Considerações finais}

A partir dos dados obtidos na pesquisa e por meio da análise da matriz estratégica de análise SWOT, foram estabelecidas algumas ações estratégicas consideradas prioritárias para a sobrevivência e melhoria da competitividade da Feira do Malhado.

Algumas ações teriam caráter imediato e poderiam ser executadas através da iniciativa dos próprios feirantes e da administração da feira, como as melhorias do ambiente interno. Outras exigirão maiores esforços e envolverão outros agentes, as quais referem-se ao ambiente externo, principalmente a necessidade de intervenção e ação da esfera pública que é responsável pela gestão da feira.

Quanto às ações internas prioritárias foram identificadas as seguintes: necessidade de mobilização dos feirantes para a organização ou reorganização do trabalho coletivo visando a busca de fontes de fomento, articulação de parcerias, encaminhamento de reinvindicações para o poder público; regularização dos feirantes que se localizam no chamado espaço da lona - feirantes que não possuem pontos fixos para comercialização e se estabelecem em áreas móveis no chão da feira para comercialização; reorganização do espaço físico para agilizar o fluxo de clientes e mercadorias; sinalização do espaço físico para identificação dos setores da feira; mapeamento do perfil dos empreendedores, saberes, produtos e serviços ofertados - criação do portfólio da Feira do Malhado; criação de um site sobre a feira, com história, mapa das lojas, layout, etc.

Em relação às ações que envolveriam o poder público e demais agentes externos, a prioridade das ações deveriam ser direcionadas ao reconhecimento oficial do espaço como atrativo turístico do município de llhéus - mercado de caráter cultural - haja vista que compõe o Inventário Turístico de Ilhéus, ISUS (2012); controle dos altos índices de violência do bairro que influenciam diretamente na falta de segurança do local - necessidade de intervenção do poder público para melhoria da segurança; resolução dos problemas com relação à coleta de lixo e saneamento da região que afetam diretamente à dinâmica do local - necessidade de intervenção do poder público para melhoria da infraestrutura e execução do projeto de revitalização física proposto no ano de 2014 pela CAR - Companhia de Desenvolvimento e Ação Regional do Estado da Bahia, órgão vinculado à Secretaria de Desenvolvimento Rural do Estado do Bahia.

O projeto de revitalização física anunciado no ano de 2007, mas foi aprovado pelo Estado da Bahia, Brasil, no ano de 2013 e previsto para a execução no ano de 2014, situação que não ocorreu até o presente momento e sem a previsão para a concretização até o ano de 2015.

A principal conclusão da pesquisa é que a Feira do Malhado de Ilhéus Bahia Brasil é um mercado tradicional e potencial que resiste a expansão dos supermercados e a lógica que predomina na expansão dos mercados capitalistas globais, mas para que sobreviva dependerá diretamente de investimentos básicos tanto na melhoria do ambiente interno, quanto ambiente externo, referente a infraestrutura e segurança do bairro no qual está inserida. Como a gestão da Feira é de responsabilidade da Prefeitura Municipal de Ilhéus, Estado da Bahia, Brasil, as melhorias prioritárias dependerão de políticas e projetos oriundos da gestão pública municipal. Iniciativas como a organização dos feirantes em associação e a mobilização dos consumidores também poderão contribuir para impulsionarem as tomadas de decisões e ações da esfera pública. 


\section{Referências bibliográficas}

BAHIATURSA. Meios de Hospedagem - Bahia. 2008. Disponível em: http://www.setur.ba.gov.br. Acesso em 23 jul. 2012.

BUSSO, M.. Las ferias comerciales: también un espacio de trabajo y socialización. Aportes para su estúdio. Trabajo y Sociedad, 16, 105-123. 2010.

BUSSO, M.; GORBAN, D. Resignificaciones identitarias en un difundido, difuso y conflictivo espacio de trabajo. Cartoneros y feriantes en calles argentinas. Ponencia presentada en el XXIV Congreso Latino Americano de Sociología, ALAS, Arequipa, Perú, del 4 al 7 de noviembre de 2003. Anais. Publicación electrónica disponible en CD. 2003.

CASTRO, A.M.G. et al. Metodologia de planejamento estratégico das unidades do MCT. Brasília, DF: Ministério da Ciência e Tecnologia, Centro de Gestão e Estudos Estratégicos, 2005.

CORRÊA, S.R.S. Avaliação social multicritério da implantação do Porto Sul, llhéus. Tese (doutorado) - Universidade Federal Rural do Rio de Janeiro, Instituto de Ciências Humanas e Sociais, Bahia, 2013.

ENDEAVOR. Entenda a Matriz Swot e as vantagens para sua empresa. Disponível em: https://endeavor.org.br/entenda-matriz-swot/. Acesso em 14 de abril de 2015.

ESTIVAL, K.G.S.; BEHRMANN, D.; RUSCIOLELLI, C. Análise Mercadológica da Central de Abastecimento do Malhado - Ilhéus - BA. Relatório de pesquisa. UESC, Ilhéus, Bahia, 2014. 70p.

FOURSQUARE. Central de Abastecimento do Malhado. Disponível em: https://pt.foursquare.com/v/central-de-abastecimentomalhado/504603e9e4b0d5f7cdbaa582. Acesso em 14 de abril de 2015.

GALDINO DANTAS, G.P. Feiras no Nordeste. Mercator, Revista de Geografia da UFC [online] 2008, 7 (Sin mes) : [Date of reference: 14 / abril / 2015] Disponível em:<http://www.redalyc.org/articulo.oa?id=273620629009 > ISSN.

GIL, A.C. Métodos e técnicas de pesquisa social. 6 ed. São Paulo: Atlas, 2010.

GUIMARÃES, C.A. A feira livre na celebração da cultura popular. 2010. $18 \mathrm{f}$. Trabalho de Conclusão de Curso (Pós-Graduação em Gestão de Projetos Culturais e Organizações de Eventos) - Centro de Estudos Latino-Americanos sobre Cultura e Comunicação, Universidade de São Paulo, 2010.

GUIRRA, G.C.S. ; Santos, A.A.P. ; Souza, L.E.; MOREAU, M.S. Evolução das taxas de violência homicida na cidade de llhéus no período entre 2003 a 2008. In: Anais do 16 Seminário de Iniciação Científica - UESC, 2010, Ilhéus. Ciência, Formação de Recursos Humanos e Desenvolvimento, 2010.

HARVEY, D. O urbanismo e a cidade: um ensaio interpretativo. In: HARVEY, D. A justiça social e a cidade. Prefácio e tradução Armando Corrêa da Silva. São Paulo: HUCITEC, 1981. p. 167-243.

HITT, M.; IRELAND, R.D.; HOSKISSON, R. Strategic management cases: competitiveness and globalization. Cengage Learning, 2012.

INSTITUTO NOSSA ILHÉUS, 2010. Dados de Ilhéus. Disponível em http://www.nossailheus.org.brl. Acesso em 18 jul. 2012. 
INSTITUTO SUPERIOR DE SUSTENTABILIDADE (ISUS). 2012. Inventário Turístico de Ilhéus. Disponível em: http://www.uesc.br/revistas/culturaeturismo/arquivos/inv ios prefeitura.pdf. Acesso em 14 de abril de 2015.

KINJO, T.; IKEDA, A. Comportamento do consumidor em Feiras Livres. In: Congresso Sociedade Brasileira de Economia e Sociologia Rural, 43, 2005. Anais... Disponível em: http://www.sober.org.br/palestra/2/420.pdf. Acesso em: 10 de abril de 2015.

KOZINETS, R.V. Netnografia: realizando pesquisa etnográfica on line. Tradução: Daniel Bueno. Porto Alegre: Penso, 2014.

NOIA, A.C. Por uma perspectiva endógena do turismo: avaliação, expectativas, participação e identidade de residentes da cidade de llhéus - BA. Dissertação de Mestrado. Universidade Estadual de Santa Cruz - Univesidade Federal da Bahia. 2008.

OLIVEIRA, D.P.R. Planejamento estratégico: conceitos, metodologias e práticas. São Paulo: Atlas Brasil. 2007.

PIERRI, M.C.P ; VALENTE, A.L.E.F. A feira livre como canal de comercialização de produtos da agricultura familiar. In: Anais do XLVIII Congresso da Sober, 2010, Campo Grande. XLVIII Congresso da Sober, 2010.

PLANO Diretor Municipal Participativo de Ilhéus. Disponível em: http://www.atil.tur.br/download/Plano\%20Diretor\%20de\%20\%20llh\%C3\%A9us\%20\%20Minuta.PDF. Acessado em 18 jun de 2013.

PROJETO ORLA DE ILHÉUS, 2007. Disponível em: http://www.iesb.org.br/biblioteca/Projeto\%200rla\%20llheus\%20final.pdf. Acessado em: 18 jul. 2012.

SILVEIRA, H. SWOT. In: TARAPANOF, K. (org.). Inteligência Organizacional e Competitiva. Brasília: Ed. UNB, 2001.

SOUZA, A.P.A. O turismo como transformador do espaço em llhéus e Itacaré, Bahia. Dissertação de Mestrado. Universidade Estadual de Santa Cruz. 2005.

TIFANY, P.; PETERSON, S. Planejamento estratégico. Editora Campus, 2000, p. 146.

\section{Nota:}

${ }^{1}$ A nomenclatura da Matriz SWOT deriva das iniciais dos termos em inglês Strengths (Forças), Weaknesses (Fraquezas), Opportunities (Oportunidades) e Threats (Ameaças), ficando conhecida em português como matriz FOFA oriunda das iniciais dos termos traduzidos. 
Katianny Gomes Santana Estival: Universidade Estadual De Santa Cruz, Ilhéus, BA, Brasil.

E-mail: ksgestival@uesc.br

Link para o currículo Lattes: http://lattes.cnpq.br/4217256031353080

Daianne Gabrielle Morais Behrmann: Universidade Estadual De Santa Cruz, Ilhéus, BA, Brasil.

E-mail: daianne_behrmann@yahoo.com.br

Link para o currículo Lattes: http://lattes.cnpq.br/0035810401254065

Camila Rusciolelli Barbosa: Universidade Estadual De Santa Cruz, Ilhéus, BA, Brasil.

E-mail: camillarb@hotmail.com

Link para o currículo Lattes: http://lattes.cnpq.br/5315513484223932

Solange Rodrigues Santos Corrêa: Universidade Estadual De Santa Cruz, Ilhéus, BA, Brasil.

E-mail: srscorrea@uesc.br

Link para o currículo Lattes: http://lattes.cnpq.br/9140625435543061

Milton Augusto Pasquotto Mariani: Universidade Federal de Mato Grosso do Sul, em Campo Grande, MS, Brasil.

E-mail: miltmari@terra.com.br

Link para o currículo Lattes: http://lattes.cnpq.br/0935409945176042

Data de submissão: 11 de janeiro de 2016

Data de recebimento de correções: 04 de maio de 2016

Data do aceite: 04 de maio de 2016

Avaliado anonimamente 